\title{
Accidental self administration of xylazine in a veterinary
}

\section{nurse}

\author{
A. Samanta, C. Roffe and K.L. Woods \\ Leicester Royal Infirmary, Leicester LE1 5WW, UK.
}

\begin{abstract}
Summary: A 19 year old male veterinary nurse accidentally injected himself with $200 \mathrm{mg}$ of xylazine (a muscle relaxant and sedative used in veterinary practice). He subsequently became comatose, hypotensive, bradycardic and acidotic. He required intensive supportive therapy, and made a full recovery over the next few hours.
\end{abstract}

Xylazine toxicity in humans is very rare, and the effects are discussed.

\section{Introduction}

Xylazine (Rompun) is extensively used in veterinary practice as a muscle relaxant and sedative. To our knowledge there have been only three documented cases of xylazine administered in humans. In all three instances this was intentionally taken, either for suicidal purposes ${ }^{1,2}$ or for pain. ${ }^{3}$ We present the first report of a case of accidental self administration of xylazine.

\section{Case report}

A 19 year old male veterinary nurse, in the process of his routine work, accidentally injected himself subcutaneously with $2 \mathrm{ml}(100 \mathrm{mg} / \mathrm{ml})$ of xylazine. There was no past medical or psychiatric history of note. He was brought to casualty by his colleagues about 30 minutes later, where he was difficult to rouse, although occasionally responsive to verbal commands.

Pupils were small and reacting sluggishly, pulse rate of 40 per minute, blood pressure $80 / 60 \mathrm{mmHg}$ and respiratory rate 10 per minute. $\mathrm{He}$ was cyanosed and hyporeflexic, with downgoing plantar responses. He was given $1.2 \mathrm{mg}$ of naloxone intravenously, with no effect. Initial haemoglobin, white cells, urea, creatinine and electrolytes were normal. Plasma glucose was $9.1 \mathrm{mmol} / \mathrm{l}$ (4.0-6.6 mmol/l). Arterial blood gases showed a pH 7.1, $\mathrm{PCO}_{2} 6.05 \mathrm{kPa}$ and $\mathrm{PO}_{2} 39 \mathrm{kPa}$ (on $60 \%$ oxygen). He rapidly became completely unrousable, was given intravenous fluids and assisted ventilation. A chest $\mathrm{X}$-ray was normal and an electrocardiogram showed sinus bradycardia between $30-40$ beats/minute. A drug screen was

Correspondence: A. Samanta, M.D., M.R.C.P. Accepted: 31 August 1989 negative. About 8 hours later he was alert and responding and was extubated. Arterial blood gases, electrolytes, plasma, glucose and creatinine were normal. Blood pressure had risen to 110 / $70 \mathrm{mmHg}$ and the heart rate was $60 / \mathrm{min}$. His clinical condition remained stable over the next 24 hours, when he was discharged from hospital.

\section{Discussion}

Xylazine [2-(2.6-dimethylphenylamino)-4-H-5,6dihydro-1.3] thiazine hydrochloride (Rompun) is commonly used in veterinary medicine as a nonnarcotic sedative for analgesia, hypnosis and muscle relaxation. ${ }^{2}$ It is a member of the 1,3 thiazines, whose chemical structure resembles the 1,4 thiazines (phenothiazines) and the tricyclic antidepressants, and whose pharmacological activity resembles clonidine. ${ }^{2}$ The usual dose in animals is $0.5-2.0 \mathrm{mg} / \mathrm{kg}$, when it produces predictable decreases in the pulse rate and respiratory rate with analgesia and sedation. This usually begins in a few minutes and lasts for up to 3 or 4 hours postinjection.

Very little of its effect is known in man. The present patient injected $200 \mathrm{mg}$ of xylazine $(3 \mathrm{mg}$ / $\mathrm{kg}$ ), and subsequently exhibited hypotension, bradycardia, respiratory and central nervous system depression, and hyperglycaemia. These clinical features were also observed in the two previously recorded cases of intentional xylazine overdose in humans. ${ }^{1,2}$

In the third case ${ }^{3}$ xylazine seems to have been administered more 'chronically' and the patient complained of attacks of blurred vision, faints and tiredness over a period of a few months, although she was noted to have a bradycardia on two separate occasions. 
Xylazine can cause profound respiratory depression, and the present patient, as well as the two earlier ones, ${ }^{1,2}$ required assisted ventilation. Xylazine acts on the alpha-2 adrenoceptors and may affect dopamine and norepinephrine storage and release. Yohimbine and tolazoline (both alpha2 adrenoceptor antagonists) are known to antagonize the sedative effects of xylazine in

\section{References}

1. Carruthers, S.G., Wexier, H.R. \& Stiller, C.R. Xylazine hydrochloride (Rompun) overdose in man. Clin Toxicol 1979, 15: $281-285$.

2. Gallanosa, A.C., Spyker, D.A., Shipe, J.R. \& Morris, D.L. Human xylazine overdose: A comparative review with clonidine, phenothianines and tricyclic antidepressants. Clin Toxicol 1981, 18: 663-678. animals. It has been suggested that yohimbine in a dose of $0.125 \mathrm{mg} / \mathrm{kg}$ may be an effective antidote to xylazine toxicity in man, ${ }^{4}$ and that this should be administered, in addition to supportive measures.

We emphasize the need for an awareness of the pharmacological effects of xylazine in humans, especially in view of its widespread use in veterinary medicine.
3. Lewis, S., O'Callaghan, C.L.P. \& Toghill, P.J. Clinical curio: Self medication with xylazine. Br Med J 1983, $287: 1369$.

4. Mackintosh, C. Potential antidote for Rompun (xylazine) in humans. NZ Med J 1985, 98: 714-715. 